\title{
Hemorragia abdominal difusa após acidente botrópico: relato de caso
}

João Wilson da Rocha 1, 4, Honolfo Elves Simões 2, Evaldo Jorge Cassoma 3

${ }^{1}$ Department of Internal Medicine, Universidade de São Paulo (USP), São Paulo, Brazil.

2 Department of Cardiology, Hospital Josina Machel, Luanda, Angola.

3 Department of Cardiology, Hospital Geral do Huambo, Huambo, Angola.

${ }^{4}$ Department of Oncology, Clínica Girassol, Luanda, Angola.

${ }^{*}$ Corresponding author: João Wilson da Rocha, Doutor Arnaldo Avenue, $n^{0} 455$. Zip Code: 01246-903 - São Paulo State, SP, Brazil. Phone: +55 (11) 3893-2000. E-mail: jwpr10@gmail.com.

Research Ethics Committee Approval (if necessary): Declaro que o paciente aprovou o estudo assinando um termo de consentimento informado e que o estudo seguiu as diretrizes éticas estabelecidas pela Declaração de Helsinque.

Received on: Aug 11, 2021. Accepted on: Sep 18, 2021. Available online: Oct 1, 2021.

\section{Abstract}

Os acidentes ofídicos causados pelo gênero Bothrops ocasionam manifestações locais secundárias à ação inflamatória aguda do veneno. A ocorrência de óbito (em torno de 0,6\% do total de casos atendidos anualmente no Brasil) é rara, mas certamente, traumática. O relato deste caso visa chamar a atenção para possíveis complicações sistêmicas (insuficiência renal e sepsis) e hemorrágicas neste tipo de envenenamento e enfatizar as medidas terapêuticas e de suporte que devem ser realizadas em tempo hábil.

Palavras-chaves: Acidente ofídico; Coagulopatia; Hemorragia abdominal; Bothrops jararaca.

\section{Introduction}

Os acidentes ofídicos representam sério problema de saúde pública nos países tropicais pela frequência com que ocorrem e pela morbimortalidade que ocasionam. Existem no mundo aproximadamente 3.000 espécies de serpentes, das quais de 10 a 14\% são consideradas peçonhentas [1].
A OMS (Organização Mundial de Saúde) calcula que ocorram no mundo 1.250 .000 a 1.665 .000 acidentes por serpentes peçonhentas por ano, com 30.000 a 40.000 mortes [2]. A mortalidade dos acidentados varia nas diferentes regiões do mundo [3].

Na Ásia, principalmente na Índia, Paquistão e Birmânia, os acidentes ofídicos provocam de $25 \mathrm{mil}$ a $35 \mathrm{mil}$ óbitos por ano, sendo uma das serpentes

ISSN: 2763-583X. doi: 10.52600/2763-583X.bjcr.2021.1.4.1-8. This is an open acess article under the CC BY license by Creative Commnons Attribution 4.0 International License. 
mais importantes a Vipera russeli [4]. Na Nigéria, ocorrem 500 casos por 100 mil habitantes, com taxa de mortalidade de 10\% [5]. Nos Estados Unidos, 12 a 15 dos 8 mil casos anuais são fatais, levando a uma mortalidade de 0,2\% [6]. $\mathrm{Na}$ África, ocorrem de 400 a 1.000 mortes por ano, causadas principalmente pelas serpentes conhecidas como Naja [4]. No Brasil, segundo dados do Ministério da Saúde, ocorrem entre 19 mil a 22 mil acidentes ofídicos por ano [3].

Existem aproximadamente 250 espécies de serpentes, sendo que destas, 70 são peçonhentas. A maioria destes acidentes deve-se a serpentes do gênero Bothrops (jararaca, jararacuçu, urutu e outros) e Crotalus (cascavel), sendo raros os produzidos por Lachesis (surucucu, surucutinga) e Micrurus (coral) [7].

As serpentes do gênero Bothrops compreendem cerca de 30 espécies, distribuídas por todo o território nacional. As espécies mais conhecidas são: B. atrox, encontradas no Norte do Brasil; B. erythromelas, encontradas na região Nordeste; $B$. neuwiedi, encontradas em todo território nacional, exceto região norte do país; $B$. jararaca, distribuídas na região Sul e Sudeste; $B$. jararacussu, encontradas no cerrado da região central e em florestas tropicais do Sudeste e a B. alternatus, distribuídas ao Sul do país [8].

Estas possuem cauda lisa, não tem chocalho e as suas cores variam muito, dependendo da espécie e da região onde vivem. São popularmente conhecidas como jararaca, ouricana, jararacuçu, urutu-cruzeira, jararaca do rabo branco, malha de sapo, patrona, surucucurana, combóia e caiçaca. Habitam zonas rurais e periferias de grandes cidades, preferindo ambientes úmidos como matas e áreas cultivadas e locais onde haja facilidade para proliferação de roedores (paióis, celeiros, depósitos de lenha). Tem hábitos predominantemente noturnos ou crepusculares [8-10].

Sua peçonha possui importantes atividades fisiopatológicas, tais com lesões locais e destruição tecidual (ação proteolítica), ativação da cascata da coagulação, podendo induzir incoagulabilidade sanguínea por consumo de fibrinogênio (ação coagulante), promove liberação de substâncias hipotensoras e provoca lesões na membrana basal dos capilares por ação das hemorraginas (ação hemorrágica), que associada à plaquetopenia e alterações da coagulação, promovem as manifestações hemorrágicas, frequentes neste tipo de acidente [7-9].

É importante ressaltar que a quantidade de veneno inoculado varia de acordo com o tamanho da serpente e, também, se ela atacou alguma outra presa recentemente [11]. No caso de serpente do gênero botrópico, há uma diferença entre o veneno do filhote, que é predominantemente coagulante, e do adulto, com maior ação proteolítica e menor ação coagulante [9]. 
O quadro clínico caracteriza-se por manifestações locais importantes como dor e edema de caráter precoce e progressivo. Frequentemente, surgem equimoses, lesões bolhosas e sangramentos no local da picada [11]. Nos casos mais graves, pode ocorrer necrose de tecidos moles com formação de abscessos e desenvolvimento de síndrome compartimental, podendo deixar como sequelas a perda funcional ou mesmo anatômica do membro acometido [8-9].

As manifestações sistêmicas incluem, além de sangramentos em ferimentos cutâneos preexistentes, hemorragias à distância como gengivorragias, epistaxes, hematêmese e hematúria. Podem ocorrer náuseas, vômitos, sudorese, hipotensão arterial e, mais raramente, choque [8,12].

As complicações sistêmicas mais comuns são o choque, a insuficiência renal aguda, a septicemia e a coagulação intravascular disseminada, tendo patogênese multifatorial e sendo causas frequentes de óbitos [8,13-14].

A confirmação laboratorial do acidente pode ser feita através de antígenos do veneno botrópico que podem ser detectados no sangue ou outros líquidos corporais do paciente, através da técnica de ELISA [8,11].

A avaliação laboratorial é realizada através do tempo de coagulação (TC), que geralmente está aumentado, bem como o tempo parcial de tromboplastina (PTT). São exames importantes para diagnóstico, conduta e evolução clínica. $\mathrm{O}$ hemograma geralmente revela leucocitose com neutrofilia e plaquetopenia de intensidade variável. O exame de urina pode apresentar proteinúria, hematúria e leucocitúria. Outros exames complementares importantes incluem dosagem de eletrólitos, uréia e creatinina, com a finalidade de detectar precocemente distúrbios hidroeletrolíticos e insuficiência renal aguda $[8,11]$.

Baseado nas alterações clínicas e laboratoriais e visando orientar a terapêutica a ser empregada, os acidentes botrópicos são classificados em casos leves, moderados e graves. $\mathrm{O}$ tratamento específico consiste na administração o mais precocemente possível, por via endovenosa do soro antibotrópico (SAB) e, na falta deste, das associações antibotrópico-crotálico (SABC) ou antibotrópico-laquético (SABL), em ambiente hospitalar [8]. Se o TC permanecer alterado 24 horas após a soroterapia, está indicada dose adicional de antiveneno [8,15].

\section{Case report}

Paciente do sexo masculino, 71 anos, previamente hígido encaminhado a unidade de emergência com relato de "picado por filhote de cobra Jararaca", no dia anterior, em polegar da mão esquerda, evoluindo com choque e coagulopatia sendo encaminhado para estabilização do quadro.

$\mathrm{O}$ paciente negava mialgias, sangramento, dor torácica, dispneia, 
diarreia. Queixava-se de leve desconforto abdominal, nauseas tontura e vómitos, e, ainda, de picada em mão direita. Referiu diurese presente, de aspecto normal. $\mathrm{O}$ paciente foi medicado por via endovenosa com 6 ampolas de Soro Amti-butrópico e Soro Fisiológico 0,9\%.

Ao exame físico, encontrava-se em bom estado geral, eupneĩco, corado, hidratado, afebril, anictérico e acianótico. $\mathrm{Na}$ ausculta cardíaca apresentava ritmos regulares, 2 tempos, bulhas hipofonéticas, pressão arterial (PA) de $86 \times 60 \mathrm{mmHg}$, murmúrio vesicular mantido sem ruídos adventícios, frequência cardíaca (FC) de 86 batimentos por minuto (bpm), frequência respiratória (FR) de 20 incursões respiratórias por minuto (irpm) saturando (SatO2)99\% de Oxigénio em ar ambiente e temperatura axilar (Tax) de 36o Celsius, abdomem flácido, doloroso a palpação difusa sem vicero-megálias, pulsos periféricos presentes sem, tempo de preenchimento capilar (TEC) menor de 4 segundos.

Solicitamos exames laboratoriais e de imagem para investigação, contudo, 20 minutos após admissão hospitalar, o paciente evolui com choque, apresentando, PA: 55x39, FC: 54 bpm tendo a necessidade de uso de droga vasoativa Noradrenalina $15 \mathrm{ml} / \mathrm{h}$. Foi prescrito Soro Anti-Botropico 3 ampolas, adicionado Hidrocortizona $500 \mathrm{mg}$.
Os exames laboratoriais, demonstraram, Hb:15; Ht:32,4; Leucócitos:9.080; Plaquetas: 156.000; Lactato:29; TGO:24; TGP:43; Bt:0,82; Bi:0,98; Ur:71; Cr:1,69; Na:138; K:3,4; CK:89; CKMB:1,9; Troponina:10,5; LDH:251; Tempo de Protrombina (TP) $>100$ segundos; INR: incoagulavel; Tempo de Tromboplastina Parcial Ativada (TTPA) 27,7 segundos; R:0,94; Fibrinogenio: $<35.0$ mg/dl; ECG: Ritmo sinusal, sem alterações electrocardiograficas de realce.

Durante a realização da tomografia paciente evolui com rebaixamento do nível de consciência após episódio de agitação, sendo medicado novamente por via endovenosa com 6 ampolas de Soro Amti-butrópico. A tomografia de Crânio apresentava estruturas normais, sem sinais de hemorragia (Figura 1).

A tomografia de tórax (Figura 2) apresentou-se com discretas áreas mal delimitadas com atenuação em vidro fosco associadas à estrias e bandas parenquimatosas nas regiões basais e seguimentos posteriores inespecificas. As demais áreas do parêquima pulmonar com atenuação preservada. Presença de espaços pleurais virtuais, ausência de linfonodomegalias mediastinais, traqueia e bronquios principais pervios e de calibre preservado, ateromatose cortiça e coronariana, vasos mediastinais com 
calibre externo preservado e coração de dimensões anatômicas preservadas.

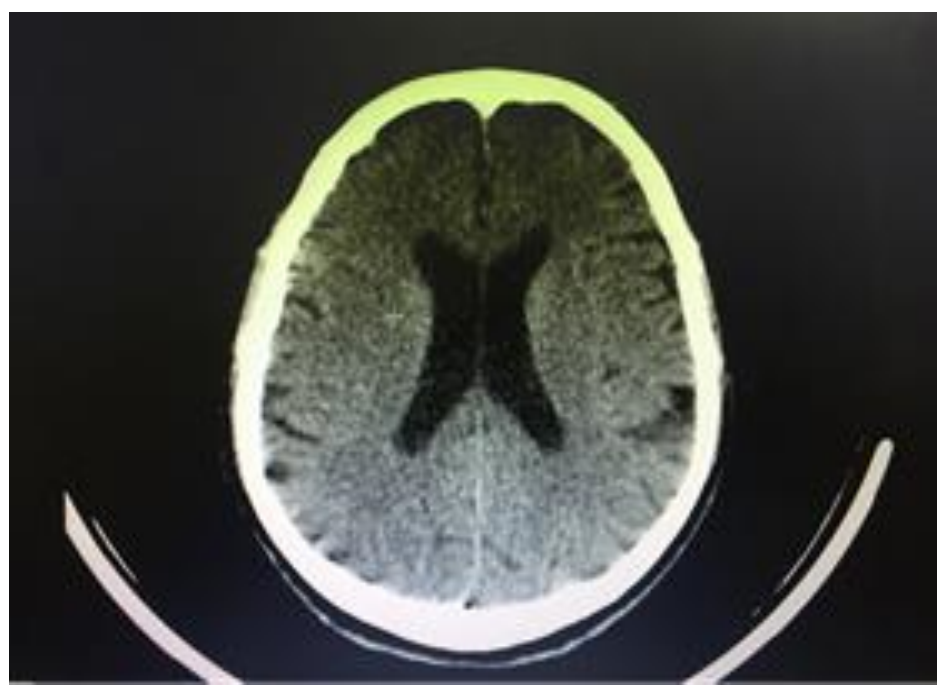

Figura 1: Tomografia do Crânio.

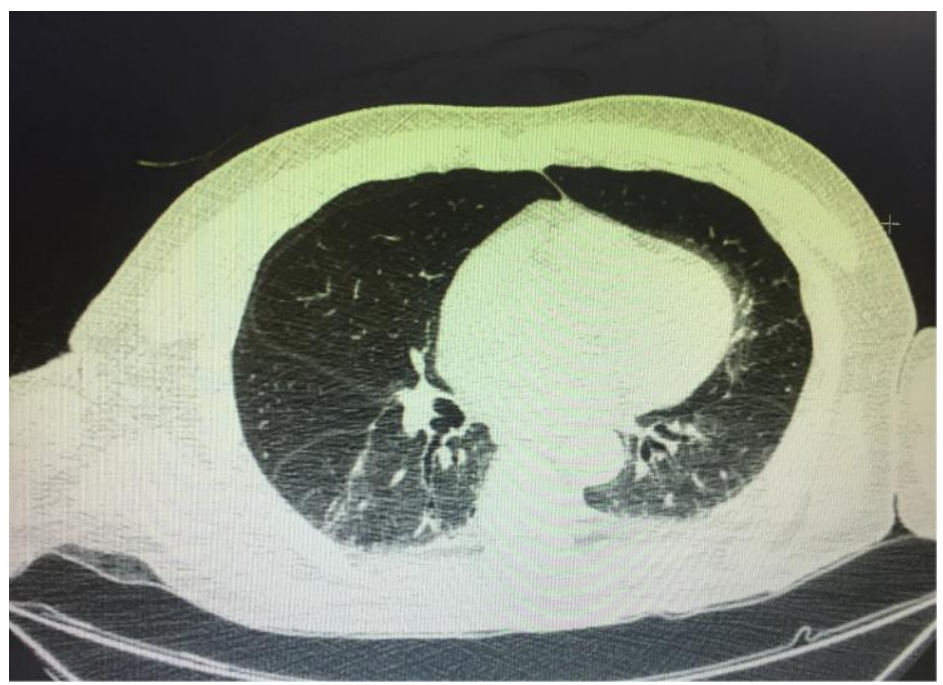

Figure 2. Tomografia do Tórax.

A tomografia de abdome total (Figura 3) moderada/grande quantidade de material hemático no interior da cavidade abdominal, predominando nos espaços peri-hepáticos e perieesplenicos. O baço foi visualizado com dimensões reduzidas, com atenuação radiologia mantida. $\mathrm{O}$ Fígado de dimensões e contornos preservados, não havia dilatação de vias biliares intra ou extra hepáticas, pâncreas e adernais de aspecto conservado. Foi identificado rins tópicos com dimensões de 
morfologia, contornos e atenuação normais. Foi identificado imagem com atenuação cistica, regular e cortical, no terço inferior renal direito medindo 9,5cm (provável cisto).

Não houveram sinais de cálculos ou hidronefrose. Observou-se ateromatose aórtica e ilíaca, aorta e veia cava inferior de calibres normais, ausência de coleções ou linfonodomegalias, hérnia gástrica hiatal, alças normodistendidas com distribuição normal. A bexiga foi apresentada sem particularidades ao método.

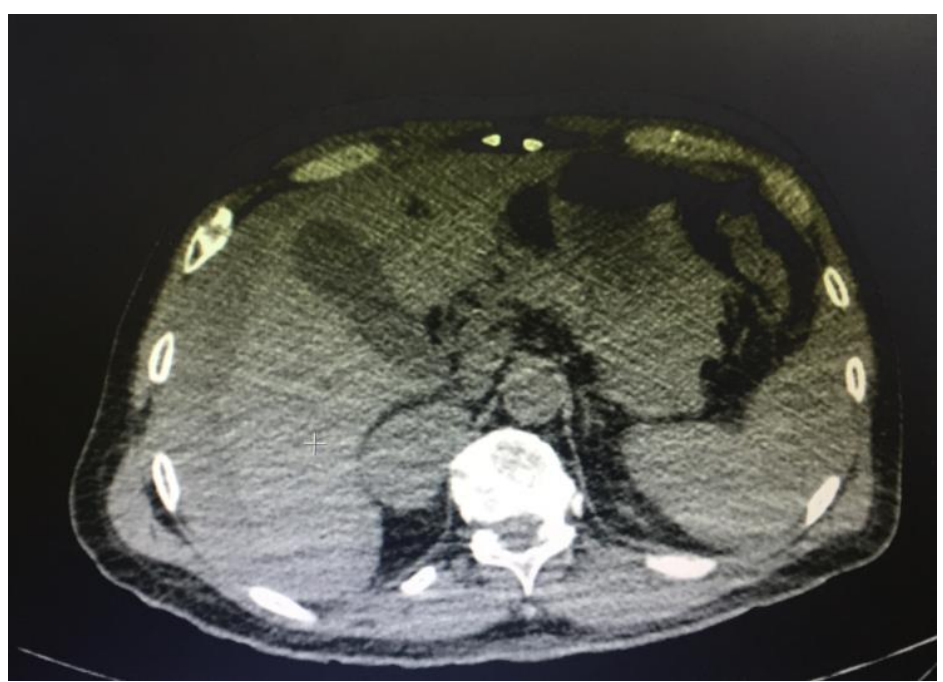

Figure 3. Tomografia do Abdomen Total.

O paciente foi internado em Unidade de Terapia Intensiva em uso de sedação e droga vasoativa (DVA) para medidas de suporte hemodinámico. Após 24 horas, o paciente evolui com melhora do choque, seguido de desligamento da DVA e sedação.

Vinte e quatro horas após a alta, o paciente apresentou melhora dos padrões laboratoriais, com TP e INR na faixa, e sem evidências de sangramento abdominal ativo. Assim, o paciente foi de alta para a enfermaria onde foi dado alta para casa $24 \mathrm{~h}$ após.

\section{Discussão e Conclusão}

A alta concentração no veneno, tem envolvimento em sintomas sistêmicos e efeitos danosos locais. A jararagina exibe ação direta no endotélio dos vasos sanguíneos e proteínas da matriz subendotelial, plaquetas, fatores de coagulação como fator de von Willebrand (vWF) e fibrinogênio, receptores de superfície celular e outros sistemas celulares como fibroblastos, epiteliais, inflamatórios e células cancerosas levando assim ao sangramento difuso.

A vítima de acidente botrópico deve receber tratamento em centro 
especializado que disponha de recursos para prover suporte adequado. Existem complicações previsíveis e possivelmente evitáveis desde que o tratamento correto seja realizado em tempo hábil. Devemos procurar sangramento em pacientes com TP e INR alterados.

\section{Referencias}

[1] Cardoso JLC, Brando RB. Acidentes por animais peçonhentos. 1a. Ed. Santos, São Paulo, 1982.

[2] Swarrop S, Grad B. Snakebite mortality in the world. Bull World Health Org. 1954; 10:35-76.

[3] Brasil. Ministério da Saúde. Ofidismo: Análise Epidemiológica. Brasília, 1991.

[4] Feitosa RFG, Melo IMLA, Monteiro HSA. Epidemiologia dos acidentes por serpentes peçonhentas no Estado do Ceará - Brasil. Rev Soc Bras Med Trop. 1997; 30(4): 295-301.

[5] Warrel DA, Arnett C. The importance of bites by the saw-scaledor carpet viper (E. carinatus). Epidemiological studies in Nigeria and a review of the world literature. Acta Trop. 1976; 33:307-341.

[6] Nelson BK. Snake envenenomation: incidence, clinical presentation and management. Med Toxicol Adver Drug. Exp 1989; 4:17-31.

[7] Amaral CFS, Rezende NA, Silva AO, Ribeiro MMF, Magalhães RA, Reis RJ,
Carneiro JG, Castro JRS. Insuficiência renal aguda secundária a acidentes ofídicos botrópico e crotálico: Análise de 63 casos. Rev Inst Med Trop. 1986; 28(4): 220-27.

[8] Brasil. Ministério da Saúde. Manual de diagnóstico e tratamento de acidentes por animais peçonhentos. Fundação Nacional de Saúde,1998.

[9] Jorge MT, Ribeiro LA. Acidentes por serpentes peçonhentas do Brasil. Rev Ass Med Bras. 1990; 36:66-77.

[10] Cupo P, Azevedo MM, Hering SE et al. Acidentes ofídicos: Análise de 102 casos. Livro de Resumos do XXI Congresso da Soc Bras Med Trop. 1990; 23-24.

[11] Filho AA. Acidentes provocados por animais peçonhentos. In: Ratton ILA. (ed). Medicina Intensiva, $2^{\text {a }}$ ed. São Paulo, Ed. Atheneu, 1997; 574-79.

[12] Burdmann EA et al. IRA nefrotóxica: Animais peçonhentos. In: Schor N, Boim MA, Santos OFP. (ed). Insuficiência renal aguda: fisiopatologia, clínica e tratamento, $1^{a}$ ed. São Paulo, Ed. Sarvier, 1997; 135-41.

[13] Ribeiro LA, Jorge MT, Iversson LB. Epidemiologia dos acidentes por serpentes peçonhentas: estudo de casos atendidos em 1988. Rev Saude Pub 1995; 5: 380-88.

[14] Ribeiro LA, Alburquerque MJ, Campos VAFP, Katz G, Takaoka NY, Lebrão ML, Jorge MT. Óbitos por serpentes peçonhentas no Estado de São 
Paulo: Avaliação de 43 casos, 1988/93.

Rev Ass Med Bras 1998; 44 (4): 312-318.

Conflitos de interesses: The author declares no conflicts of interest.

Agradecimentos: None.

Financiamento: None.

Como citar este artigo: Rocha JW, Simões HE, Cassoma EJ. Hemorragia abdominal difusa após acidente botrópico: relato de caso. Brazilian Journal of Case Reports. 2021 JulSep;01(4):1-8. 